\title{
Evidence of Tri-Exponential Decay for Liver Intravoxel Incoherent Motion MRI: A Review of Published Results and Limitations
}

\author{
Olivier Chevallier ${ }^{1} @$, Yì Xiáng J. Wáng ${ }^{2}$, Kévin Guillen ${ }^{1}$, Julie Pellegrinelli ${ }^{1}$, Jean-Pierre Cercueil ${ }^{1}$ \\ and Romaric Loffroy $1, *$ (i)
}

1 Image-Guided Therapy Center, Department of Vascular and Interventional Radiology, François-Mitterrand University Hospital, 14 Rue Paul Gaffarel, BP 77908, 21079 Dijon, France; olivier.chevallier@chu-dijon.fr (O.C.); kguillen@hotmail.fr (K.G.); julie.pellegrinelli@chu-dijon.fr (J.P.); jpcercueil@gmail.com (J.-P.C.)

2 Department of Imaging and Interventional Radiology, Faculty of Medicine, The Chinese University of Hong Kong, New Territories, Hong Kong, China; yixiang_wang@cuhk.edu.hk

* Correspondence: romaric.loffroy@chu-dijon.fr; Tel.: +33-380-293-677

check for updates

Citation: Chevallier, O.; Wáng, Y.X.J.; Guillen, K.; Pellegrinelli, J.; Cercueil,

J.-P.; Loffroy, R. Evidence of

Tri-Exponential Decay for Liver

Intravoxel Incoherent Motion MRI: A Review of Published Results and

Limitations. Diagnostics 2021, 11, 379.

https://doi.org/10.3390/

diagnostics11020379

Academic Editor: Stefano Palmucci

Received: 28 January 2021

Accepted: 20 February 2021

Published: 23 February 2021

Publisher's Note: MDPI stays neutral with regard to jurisdictional claims in published maps and institutional affiliations.

\begin{abstract}
Diffusion weighted imaging (DWI) and intravoxel incoherent motion (IVIM) have been explored to assess liver tumors and diffused liver diseases. IVIM reflects the microscopic translational motions that occur in voxels in magnetic resonance (MR) DWI. In biologic tissues, molecular diffusion of water and microcirculation of blood in the capillary network can be assessed using IVIM DWI. The most commonly applied model to describe the DWI signal is a bi-exponential model, with a slow compartment of diffusion linked to pure molecular diffusion (represented by the coefficient $\mathrm{D}_{\text {slow }}$ ), and a fast compartment of diffusion, related to microperfusion (represented by the coefficient $\mathrm{D}_{\text {fast }}$ ). However, high variance in $\mathrm{D}_{\text {fast }}$ estimates has been consistently shown in literature for liver IVIM, restricting its application in clinical practice. This variation could be explained by the presence of another very fast compartment of diffusion in the liver. Therefore, a tri-exponential model would be more suitable to describe the DWI signal. This article reviews the published evidence of the existence of this additional very fast diffusion compartment and discusses the performance and limitations of the tri-exponential model for liver IVIM in current clinical settings.
\end{abstract}

Keywords: diffusion weighted imaging; intravoxel incoherent motion; liver; tri-exponential; b-value

\section{Introduction}

Diffusion weighted imaging (DWI) sequence has shown high-performance for the detection of malignant liver tumors, particularly liver metastases from solid cancer [1-4]. There is a growing interest for diffused liver diseases assessment using DWI sequence, particularly for liver fibrosis detection and staging, but also for liver inflammation [5-12]. New treatments might slow or stop the progression of liver fibrosis [13]. For treatment monitoring, a noninvasive method, such as liver DWI, is required. Initially, DWI signal was described as a mono-exponential decay model, owing to a mono-compartmental model of water diffusion [14,15]. In 1986, an additional compartment of diffusion, related to the microcirculation of blood, was described by Le Bihan et al. and the principle of intravoxel incoherent motion (IVIM) was introduced [16,17]. According to IVIM theory, two diffusion compartments can be assessed: a fast compartment of diffusion, related to microperfusion (represented by $\mathrm{D}_{\text {fast}}$, or $\mathrm{D}^{*}$ ), and a slow compartment linked to pure molecular diffusion (represented by $\mathrm{D}_{\text {slow }}$, or $\left.\mathrm{D}\right)[17,18]$. Therefore, a bi-exponential decay model was used to describe the signal decay. Numerous studies aiming to assess diffused liver diseases using this two-compartment model have been published [7,9,19]. However, high variance in $\mathrm{D}_{\text {fast }}$ estimates has been consistently shown in literature, restricting its application in clinical practice [9]. This variance could be due to an additional perfusion 
component [20]. In addition, liver is anatomically and physiologically quite complex, with presence of several vessels types (arteries/arterioles, portal veins/venules), sinusoid capillaries, bile ducts, lymphatic system, and the space of Disse, which is a functionally important intermediate area of exchange between the sinusoids and hepatocytes [21]. Since flowing or moving spins are present in these compartments, which are directly or indirectly connected together, it can be hypothesized that more than two compartments of diffusion exist in the liver and could be analyzed through the recorded DWI signal decay. Recently, evidence of the existence of an additional very fast component of diffusion in the liver has been published [20,22-26]. Therefore, a tri-exponential decay model has been proposed. The aim of this article is to review and discuss the published evidence of a tri-exponential decay behavior of the DWI signal, but also the technical requirements and the limitations of the tri-exponential IVIM model in current clinical settings.

\section{Classic DWI Mono-Compartmental Model}

Molecular diffusion, which is due to microscopic random translational motion of molecules in a fluid, can be studied by a diffusion model [16]. The diffusion coefficient $D$ is related to molecular mobility. For pure water, $D=2.5 \times 10^{-3} \mathrm{~mm}^{2} / \mathrm{s}$ and $D=2.3 \times 10^{-3} \mathrm{~mm}^{2} / \mathrm{s}$ at 40 and $25{ }^{\circ} \mathrm{C}$, respectively [16,17]. Restricted diffusion phenomenon is observed in fluids when diffusion is restricted to a limited volume, such as intracellular water. A phase shift is produced by the displacement of spins during the time of echo (TE) in the presence of diffusion gradients [16,17]. The loss of phase coherence in the transverse magnetization results in an attenuation of the DWI signal.

Considering mono-compartmental model of diffusion, the DWI signal is regarded as related to the random Brownian motion of water molecule, molecular diffusion. The signal attenuation as a function of $\mathrm{b}$ is thus expressed using mono-exponential decay model with the following equation:

$$
\mathrm{SI}_{\mathrm{b}}=\mathrm{SI}_{0} \cdot \exp (-b \cdot \mathrm{ADC})
$$

where $\mathrm{SI}_{\mathrm{b}}$ is the signal intensity at the given $b$ value (weighted signal), $\mathrm{SI}_{0}$ denotes the signal intensity at $\mathrm{b}=0 \mathrm{~s} / \mathrm{mm}^{2}$ (unweighted signal) which is proportional to $\mathrm{e}^{-\mathrm{TE} / \mathrm{T} 2}$, and $\mathrm{ADC}$ is the apparent diffusion coefficient.

In the presence of restricted diffusion, ADC is reduced.

\section{IVIM Theory, Bi-Compartmental Model}

Le Bihan et al. demonstrated that the separation of two different anatomical compartments was feasible in the voxel: an intracellular compartment in which molecular diffusion can be assessed, and an extracellular compartment in which the spins' motions present higher velocities [17].

According to IVIM theory, diffusion is considered bi-compartmental with a fast component of diffusion, related to microcirculation, called pseudo-diffusion, and a slow component of diffusion, linked to pure molecular diffusion. The signal attenuation as a function of $b$ is modeled according to a bi-exponential equation:

$$
\mathrm{SI}_{\mathrm{b}}=\mathrm{SI}_{0} \cdot\left[\mathrm{PF} \cdot \exp \left(-b \cdot \mathrm{D}_{\mathrm{fast}}\right)+(1-\mathrm{PF}) \cdot \exp \left(-b \cdot \mathrm{D}_{\text {slow }}\right)\right]
$$

where PF (also called $\mathrm{f}$ ) represents the fraction of the pseudo-diffusion compartment, $\mathrm{D}_{\text {fast }}$ (also called $\mathrm{D}^{*}$ ) is the pseudo-diffusion coefficient representing the incoherent microcirculation within the voxel (perfusion-related diffusion) and $\mathrm{D}_{\text {slow }}$ (also called $\mathrm{D}$ ) is the diffusion coefficient representing the slow (pure) molecular diffusion. In addition, the expression (1-PF) represents the fraction of the molecular diffusion compartment.

$D_{\text {fast }}$ values demonstrate high variance between studies, restricting its application in clinical practice. Particularly, $\mathrm{D}_{\text {fast }}$ is underestimated when few low b-values are included, while it tends to increase when more very low b-values are included $[9,27]$. $D_{\text {fast }}$ value is thus very dependent of the lowest nonzero b-value of the DWI acquisition. Figure 1 shows the 
dependency of $\mathrm{D}_{\text {fast }}$ on the low and very low b-values included in the b-value distribution. This suggests that bicompartmental model may not be suitable for the fit of liver DWI.

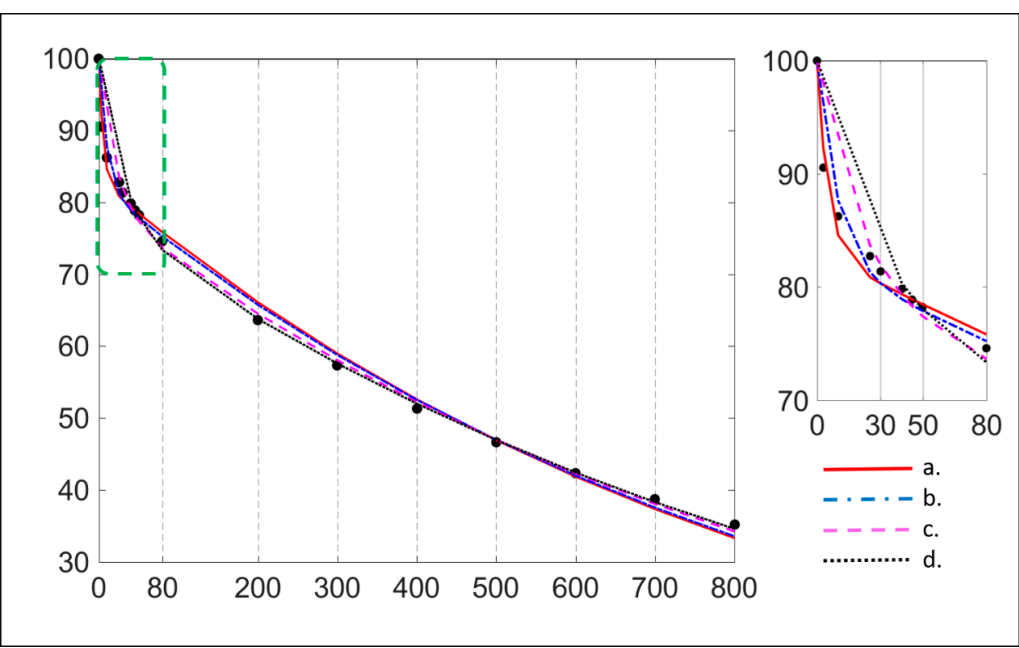

Figure 1. Comparison diffusion weight imaging (DWI) signal fits with the bi-exponential model (full fitting method) using 16 b-values $(0,3,10,25,30,40,45,50,80,200,300,400,500,600,700$, $800 \mathrm{~s} / \mathrm{mm}^{2}$ ) (a) and after the successive removal of very low and low b-values (b, c, d). After the successive removal of very low and low b-values, the initial slope of the fitted-curve becomes less and less steep; the $D_{\text {fast }}$ value therefore decreases. Notice that the $D_{\text {slow }}$ value also decreases, while the PF value increases. (b), $b=3 \mathrm{~s} / \mathrm{mm}^{2}$ removed; (c), $\mathrm{b}=3,10 \mathrm{~s} / \mathrm{mm}^{2}$ removed; $(\mathrm{d}), \mathrm{b}=3,10,25$, $30 \mathrm{~s} / \mathrm{mm}^{2}$ removed; $\mathrm{D}_{\text {fast }}=193.6,103.6,48.1$, and $35.2 \times 10^{-3} \mathrm{~mm}^{2} / \mathrm{s}, \mathrm{D}_{\text {slow }}=1.14,1.12,1.06$, and $1.02 \times 10^{-3} \mathrm{~mm}^{2} / \mathrm{s}$, and $\mathrm{PF}=16.9 \%, 17.7 \%, 20.3 \%$, and $21.8 \%$, for (a); (b); (c), and (d), respectively.

\section{Tri-Compartmental Model}

The use of a tri-exponential model for IVIM has two goals: first, a better assessment of molecular diffusion by applying a model that is more consistent with the recorded signal decay; second, a separation of two fast diffusion compartments, which are related to extracellular spins' motions and observed at low and very-low b-values.

\subsection{Equation}

If diffusion is considered as tri-compartmental, the signal attenuation as a function of $\mathrm{b}$ is expressed by a tri-exponential equation [22,24]:

$$
\mathrm{SI}_{\mathrm{b}}=\mathrm{SI}_{0} \cdot\left[\mathrm{F}^{\prime}{ }_{\text {Vfast }} \cdot \exp \left(-b \cdot \mathrm{D}_{\text {Vfast }}^{\prime}\right)+\mathrm{F}_{\text {fast }}^{\prime} \cdot \exp \left(-b \cdot \mathrm{D}_{\text {fast }}^{\prime}\right)+\mathrm{F}_{\text {slow }}^{\prime} \cdot \exp \left(-b \cdot \mathrm{D}_{\text {slow }}^{\prime}\right)\right]
$$

where $\mathrm{D}_{\text {fast }}^{\prime}$ and $\mathrm{D}^{\prime}$ Vfast represent the fast and very fast perfusion-related and pseudodiffusion coefficients and $\mathrm{D}_{\text {slow }}$ represents the molecular diffusion coefficient, thus being similar to $\mathrm{D}_{\text {slow }}$. $\mathrm{F}_{\text {slow }}, \mathrm{F}_{\text {fast }}^{\prime}$ and $\mathrm{F}_{\text {vfast }}$ are the fractions of each compartment. $\mathrm{F}_{\text {slow }}^{\prime}$ is similar to the fraction of the slow diffusion compartment (1-PF), and the combination of $\mathrm{F}_{\text {fast }}^{\prime}+\mathrm{F}^{\prime}$ Vfast is similar to PF of the bi-exponential model.

\subsection{Evidence for Tri-Exponential Decay Model}

The presence of multiple perfusion components in the DWI signal has been discussed in several studies [28-30]. Recent articles suggest the presence of two perfusion components of diffusion, a very fast compartment of diffusion, represented by the parameters $\mathrm{D}^{\prime}{ }_{\text {Vfast }}$ and $\mathrm{F}^{\prime}{ }_{\text {Vfast }}$, and a fast compartment of diffusion represented by the parameters $\mathrm{D}_{\text {fast }}^{\prime}$ and $\mathrm{F}_{\text {fast }}$.

The study of Cercueil et al. aimed to compare mono-, bi- and tri-exponential models in order to determine which of them best fits the IVIM signal of normal liver. In total, 38 and 36 patients for pilot and validation studies were included, respectively [22]. The chosen b-values were $0,5,15,25,35,50,100,200,400,600,800 \mathrm{~s} / \mathrm{mm}^{2}$ for the pilot study and $0,5,10,15,20,25$, $30,35,40,45,50,100,200,400,600,800 \mathrm{~s} / \mathrm{mm}^{2}$ for the validation study. Since modeling the 
IVIM signal in a single patient can be challenging, the MR signals of all study participants were averaged together, as it has been previously proposed in order to improve the signal to noise ratio (SNR) [31,32]. Parameters were calculated using a nonlinear least-squares full fitting method. Using the extra sum-of-squares F-test and information criteria to compare the models, Cercueil et al. demonstrated that the tri-exponential model provided a better fit for IVIM signal, with the differences in Akaike information criterion (AIC) and corrected AIC (AICc) scores being strongly in favor of the tri-exponential model.

Using an ingenious adaptive multiexponential IVIM model, Kuai et al. investigated the effect of multiple perfusion components on the measurement of $\mathrm{D}_{\text {fast }}$ using simulated data [20]. The same adaptive method was used on abdominal DWI acquisitions of 31 volunteers to determine the number of perfusion components in the liver, the spleen, and the kidney [20]. Two perfusion components were found in the liver and the spleen, with larger difference between perfusion components in the liver than in the spleen, whereas only one perfusion component was found in the kidney. However, the kidney presents intermediate IVIM perfusion compared to the liver that presents high IVIM perfusion. The extraction of another perfusion component might be more challenging in the kidney [33]. In addition, the liver and spleen show higher $\mathrm{D}_{\text {fast }}$ values compared to the kidney [33]. Moreover, regions of interests (ROI) were positioned without discriminating the cortex and the medulla in this study, although these tissues might present different signal decay $[23,34]$. For the liver and the spleen, the fitting residuals from the multiexponential adaptive IVIM model, with two perfusion components, were significantly smaller than those from the bi-exponential model. Kuai et al. results also implied that the observed high variance of $\mathrm{D}_{\text {fast }}$ in literature with bi-exponential model could be explained by the presence of multiple perfusion components in the DWI signal [20].

With an extensive DWI protocol including $68 \mathrm{~b}$-values ranging from 0 to $1005 \mathrm{~s} / \mathrm{mm}^{2}$, a study aimed to assess the number of distinguishable diffusion components in healthy liver, spleen and kidneys [23]. As the T2 relaxation spectra method has been used to assess the multiple components of $\mathrm{T} 2$ relaxation in tissues, the computation of apparent diffusion coefficient 'spectra' (ADC 'spectra') was performed in this study to describe the characteristics and relative contributions of the different diffusion components [35,36]. Eight healthy subjects were included. In addition to the known two components of diffusion proposed by the IVIM model, a third component of diffusion was detected in the liver, in the kidney cortex and medulla, but not in the spleen, where only two diffusion components were observed [23]. Unlike the Kuai et al. study, distinct ROIs were positioned on the kidney cortex and the medulla. This may explain the discrepancy between these two studies concerning the number of detected compartments in the kidney $[20,23,34]$.

Chevallier et al. analyzed the liver DWI signal of 50 scans from 18 volunteers with 16 b-values $\left(0,3,10,25,30,40,45,50,80,200,300,400,500,600,700\right.$, and $\left.800 \mathrm{~s} / \mathrm{mm}^{2}\right)$ [24]. Volunteers were scanned twice in a first session, then once in a second session, in order to assess the parameters' repeatability and reproducibility. For each scan, image series contaminated by evidential physiological motion and other artifacts were manually removed [37]. Data from each scan were then fitted using bi-exponential and tri-exponential decay models, using full fitting and segmented fitting methods. In addition to the IVIM parameters estimation based on individual scans, the measured signals at each b-value from the 50 scans were additionally averaged together; the averaged signals (total-averaged) were then fitted with the four approaches as they were from a single scan [22,32]. Adjusted $\mathrm{R}^{2}$, extra-sum-of-squares F-test and AICc were used for model and fitting method comparison. Overall, for the individual scans, the tri-exponential model was favored over the bi-exponential model. Among the 50 individual scans, tri-exponential model was favored for 44 to 50 scans with F-test and for 42 to 49 scans with AICc (depending on the fitting methods). The same finding was observed with the total-averaged fits, with AICc analysis strongly suggesting that bi-exponential model was unlikely to be correct compared to tri-exponential model. For the total-averaged data fits, according to the evidence ratio, tri-exponential model with full fitting method was $1.60 \times 10^{11}$ times more likely to be 
correct than bi-exponential model with full fitting method. Figure 2 shows the fitting curves obtained with the four methods and total-averaged data. In addition, graphical analysis of the residuals of the fits versus each b-value demonstrated that the tri-exponential model presented smaller and more randomly distributed residuals compared with the bi-exponential model (Figure 3). With the bi-exponential model, the residuals were not randomly scattered showing systematic patterns, therefore suggesting autocorrelation in the residuals and that the bi-exponential model may be unsuitable [38].

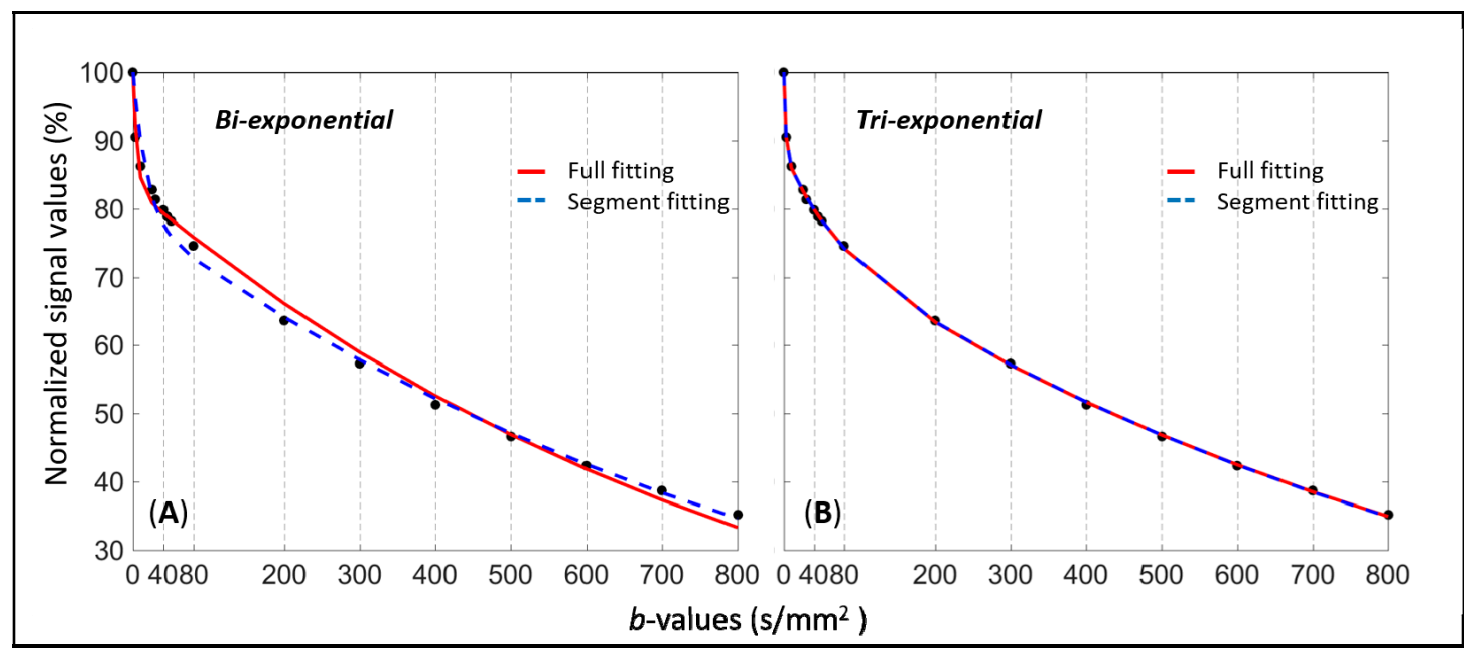

Figure 2. A comparison of signal fitted curves using bi-/tri-exponential models with full or segmented fitting (b-value threshold $=200 \mathrm{~s} / \mathrm{mm}^{2}$ ). (A) For the bi-exponential model, both fittings do not fit well the initial part of the diffusion signal decay. (B) For the tri-exponential model, both fittings show a good fit of diffusion signal decay, with the two fitted curves almost indistinguishable.

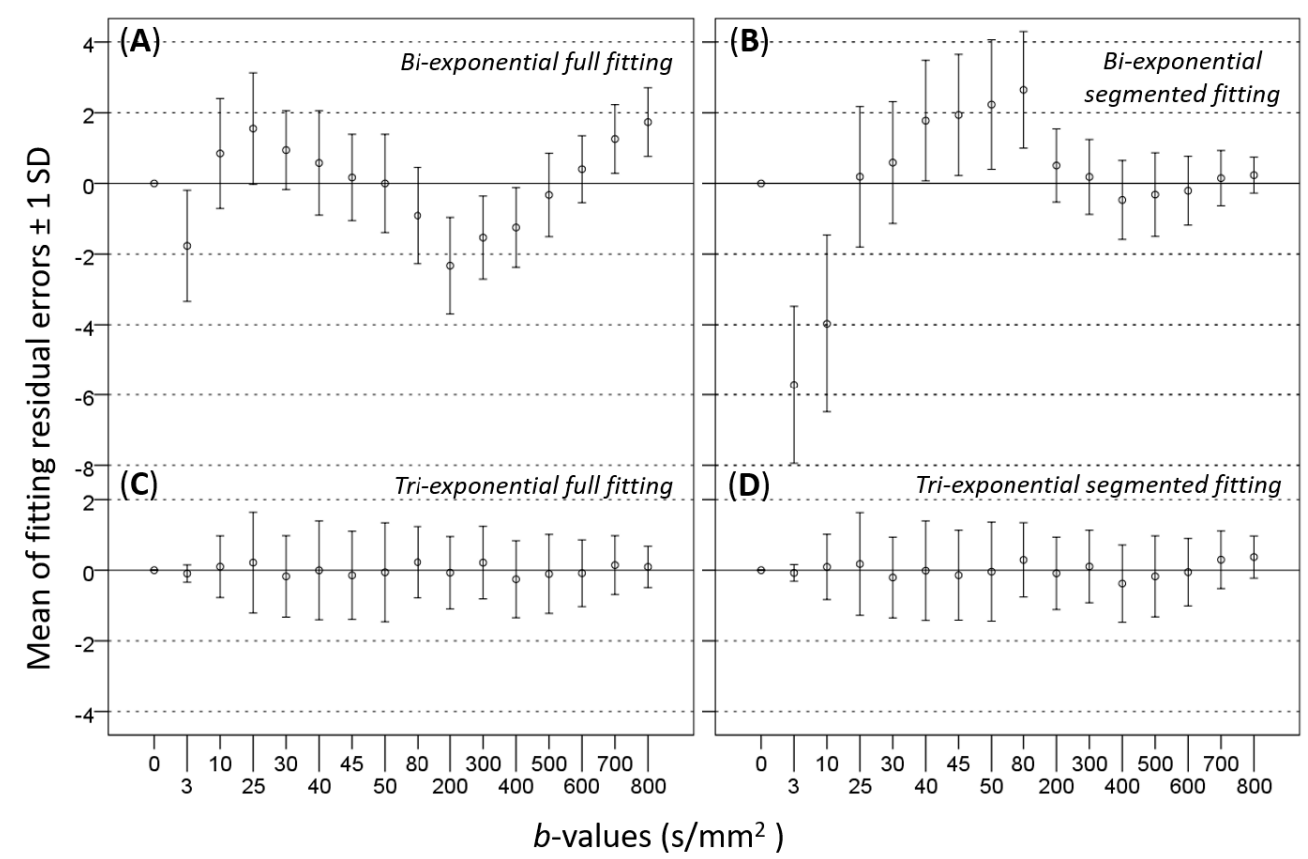

Figure 3. Residuals distribution from the fits of 50 individuals DWI scans using bi-/tri-exponential models with full or segmented fitting ( $b$-value threshold $=200 \mathrm{~s} / \mathrm{mm}^{2}$ ). Error bars: mean $\pm \mathrm{SD}$ (in \%, $n=50$ scans). Bi-exponential model (A,B) shows strong errors in predicted signal. The residuals in (A,B) are not randomly scattered showing systematic patterns, therefore suggesting autocorrelation in the residuals. Tri-exponential models $(\mathbf{C}, \mathbf{D})$ show smaller and more random distribution of the residuals. 
In a study aiming at investigating the dependency of IVIM parameters on the used $\mathrm{B}_{0}$ field strength, the tri-exponential model was explored [25]. With 20 healthy volunteers, the DWI signal of the liver was fitted with bi-exponential and tri-exponential models. Numerous very low b-values images were acquired $\left(14 \mathrm{~b}\right.$-values $\left.<5 \mathrm{~s} / \mathrm{mm}^{2}\right)$. AICc were calculated for model comparison and the probability that the tri-exponential was more appropriate was larger than $99.999 \%$ for all volunteers [25].

Another study was conducted in order to find optimized b-values that reduce the fit uncertainty in all tri-exponential parameters [26]. With simulated data, AIC comparison favored the bi-exponential model if the number of b-values was small, whereas it favored the tri-exponential model if more $b$-values were added to the $b$-values distribution. In addition, when the SNR increased, less b-values were required to favor the tri-exponential model. AIC comparison also indicated that the tri-exponential model was better suited to describe the data than the bi-exponential model for in vivo measurement with three volunteers.

Characteristics of the studies comparing tri-exponential and bi-exponential models for liver IVIM are shown in Table 1.

Table 1. Characteristics of the studies comparing tri-exponential and bi-exponential models for liver IVIM.

\begin{tabular}{|c|c|c|c|}
\hline Authors, Year & No. of Subjects & No. of Scans & Fitting Comparison Methods \\
\hline \multirow[t]{2}{*}{ Cercueil et al., 2015 [22] } & $38^{\#}$ & $38^{\#}$ & \multirow{2}{*}{$\begin{array}{l}\text { Extra sum-of-squares F-test } \\
\text { and AIC, AICc }\end{array}$} \\
\hline & 36 \#\# & $36^{\# \#}$ & \\
\hline Kuai et al., 2017 [20] & 31 & 31 & Fitting residuals data \\
\hline Chevallier et al., $2019 *[24]$ & 18 & 50 & $\begin{array}{c}\text { Adjusted-R }{ }^{2} \\
\text { Extra sum-of-squares F-test } \\
\text { AIC, AICc } \\
\text { Graphical analysis of the residuals }\end{array}$ \\
\hline Riexinger et al., 2019 ** [25] & 20 & 40 & $\mathrm{AICc}$ \\
\hline Riexinger et al., 2021 [26] & 3 & 3 & AIC \\
\hline
\end{tabular}

No, number; AIC, Akaike information criterion; AICc, corrected Akaike information criterion. * volunteers had their liver scanned twice in the same session and then once in another session. Four scans were excluded due to bad quality of the images. ** abdominal data of volunteers were acquired in two consecutive measurements at $1.5 \mathrm{~T}$ and 3T. " pilot study; ${ }^{\# \#}$ validation study.

As mentioned previously, other abdominal organs might also demonstrate a triexponential decay behavior of the DWI signal [20,23,34]. In a recent study, authors tested the incorporation of a third component of diffusion in the IVIM model for kidney tissue assessment, since there is both perfusion of the blood vessels and flow of pre-urine through the tubuli and collecting ducts in the kidney [39]. With a DWI protocol including $16 \mathrm{~b}$-values $\left(0,2,4,8,12,18,24,32,40,50,75,110,200,300,450,600 \mathrm{~s} / \mathrm{mm}^{2}\right)$ and a group of eight healthy volunteers that were scanned at baseline and during three increasing doses of continuous intravenous Angiotensin II infusion, this study demonstrated that tri-exponential analysis was able to detect changes in renal perfusion during pharmacologically induced renal perfusion modulation. Parameter $\mathrm{F}_{\text {fast }}$ correlated with the glomerular filtration rate, while there was an inverse correlation between the parameter $\mathrm{F}^{\prime}$ Vfast and the renal plasma flow [39]. Note that both coefficients $\mathrm{D}_{\text {fast }}^{\prime}$ and $\mathrm{D}^{\prime}{ }_{\text {Vfast }}$ were fixed in order to improve the robustness of the model. Therefore, tri-exponential model for IVIM might also be preferable for other abdominal organs' assessments.

\subsection{Tri-Exponential Model Fitting Methods.}

As for bi-exponential fitting, full fitting [22,24] and segmented fitting [24-26] methods have been used for the tri-exponential model. The full fitting method was performed using nonlinear least squares regression model-based algorithm [22,24]. By definition, the sum of the fraction of each compartment is equal to $1\left(\mathrm{~F}_{\text {slow }}^{\prime}+\mathrm{F}_{\text {fast }}^{\prime}+\mathrm{F}_{\text {vfast }}^{\prime}=1\right)$. Therefore, tri-exponential function can be reduced to five rather than six parameters to solve [24-26]. For instance, the parameter $\mathrm{F}^{\prime}$ vfast can be removed from the equation, leading to:

$\mathrm{SI}_{\mathrm{b}}=\mathrm{SI}_{0} \cdot\left[\left(1-\mathrm{F}_{\text {fast }}^{\prime}-\mathrm{F}_{\text {slow }}^{\prime}\right) \cdot \exp \left(-b \cdot \mathrm{D}_{\text {Vfast }}^{\prime}\right)+\mathrm{F}_{\text {fast }}^{\prime} \cdot \exp \left(-b \cdot \mathrm{D}_{\text {fast }}^{\prime}\right)+\mathrm{F}_{\text {slow }}^{\prime} \cdot \exp \left(-b \cdot \mathrm{D}_{\text {slow }}^{\prime}\right)\right]$ 
Segmented fitting method consists of a two-step approach. It is commonly accepted that only the slow diffusion compartment contributes significantly to the DWI signal for b-values higher than 100-200 s/ $\mathrm{mm}^{2}$ [9,24-26,37,40-43]. Therefore, the estimation of $\mathrm{D}_{\text {slow }}$ can first be obtained by a linear fit using only b-values above a certain b-value threshold (generally, 100-200 s/ $\mathrm{mm}^{2}$ ). Second, the obtained $\mathrm{D}^{\prime}{ }_{\text {slow }}$ can be substituted into Equation 4 and a nonlinear regression using all b-values allows the estimate of the other four parameters $[25,26]$. Moreover, after the first step of segmented fitting method, $\mathrm{F}_{\text {slow }}$ can be estimated as by extrapolation of the curve at $\mathrm{b}=0 \mathrm{~s} / \mathrm{mm}^{2}$, leading to calculate $\mathrm{F}^{\prime}$ slow as $\mathrm{SI}_{\mathrm{int}} / \mathrm{SI}_{0}$ where $\mathrm{SI}_{\mathrm{int}}$ is the $\mathrm{b}=0 \mathrm{~s} / \mathrm{mm}^{2}$ intercept of the fit $[37,41,43]$. Therefore, both parameters $\mathrm{D}_{\text {slow }}$ and $\mathrm{F}_{\text {slow }}$ can be substituted into Equation 4, reducing the number of unknown parameters to three rather than four for the nonlinear fit [24].

In the Chevallier et al. study, while full fitting method was slightly favored versus segmented fitting method in terms of fit performance, the differences remained negligible [24]. However, scan-rescan repeatability and reproducibility of parameters were better with the segmented fitting method than with the full fitting method, apart from $\mathrm{D}^{\prime}{ }_{\mathrm{Vfast}}$ for which the results were similar [24]. In addition, for both fitting methods, starting points and boundary constraints can be introduced to improve the fit $[24-26,37,40]$.

The calculation of the parameters in an adaptive manner has also been explored using an adaptive multiexponential IVIM model [20]. New perfusion components are added gradually to the equation, depending on the signal attenuation ratio at b-values inferior to $\mathrm{b}$-values related to the last diffusion compartment that was detected. This method permits to assess the number of perfusion components and the calculation of the parameters in a progressive manner.

A quite different method has been proposed, that consists of fitting the DWI signal in a non-negative least-squares manner to a distribution of decaying exponential function using minimum-amplitude energy regularization [23]. From the resulting ADC spectra, the diffusion coefficients can be extracted. Based on our understanding, the main goal of this method is to identify the number of diffusion components in abdominal organs.

All these studies used a ROI-based analysis method, which offers better estimation than pixel-fitting method when the SNR is low [44,45].

Other methods that introduced a spatially constrained incoherent motion model of the DWI signal decay and an efficient iterative "fusion bootstrap moves" solver have been proposed and might improve the accuracy and robustness of IVIM parameters estimates $[46,47]$. Bayesian fitting method has been tested for the bi-exponential model and may lead to a more robust estimation [48-50]. A novel segmented Bayesian method was also proposed and explored on simulated images and real data of patients with headand-neck and rectal cancers [51]. This last method was also studied in combination with spatial regularization through a conditional autoregressive prior specification and has shown promising results [51]. Recently, neural-network-based fit approaches have been tested for bi-exponential IVIM with interesting results [52,53]. However, to our knowledge, none of these algorithms have been tested for the tri-exponential model. Regarding the positive results of Bayesian and artificial neural-network based methods for bi-exponential IVIM model, it is very likely that they would improve the accuracy and robustness of tri-exponential parameters.

Based on the assumption that the very fast compartment of diffusion is related to the presence of large blood vessels in the ROI that are not visually identified, other authors considered the very fast-decaying component in the DWI signal as a blood-flow rather than a tissue perfusion [54]. They proposed a new algorithm that considers spatial constraints on a tri-exponential IVIM model dealing simultaneously with the all voxels in the ROI. This method allows an automatic detection of this very fast component of diffusion and provides both the spatial distributions of all the IVIM parameters over the defined ROI and the parameters estimates $[54,55]$. 


\subsection{Tri-Exponential Parameters Values in Healthy Liver}

Published values of tri-exponential parameters are shown in Table 2. Main acquisition parameters for DWI sequence by studies are shown in Table 3. Overall, four studies demonstrate similar diffusion coefficients values, with $\mathrm{D}^{\prime}{ }_{\text {Vfast }}$ ranging from 380 to $500 \times 10^{-3} \mathrm{~mm}^{2} / \mathrm{s}, \mathrm{D}_{\text {fast }}^{\prime}$ ranging from 16 to $26.5 \times 10^{-3} \mathrm{~mm}^{2} / \mathrm{s}, \mathrm{D}_{\text {slow }}^{\prime}$ ranging from 0.98 to $1.35 \times 10^{-3} \mathrm{~mm}^{2} / \mathrm{s}[20,22,24,26]$. $\mathrm{D}_{\text {slow }}^{\prime}$ is consistent with literature reports and bi-exponential model [9]. In a previous study where the lowest b-value was $b=10 \mathrm{~s} / \mathrm{mm}^{2}$, thus reducing the tri-compartmental model to a bi-compartmental model, the $\mathrm{D}_{\text {fast }}$ value was $12.34 \times 10^{-3} \mathrm{~mm}^{2} / \mathrm{s}$ [12]. Although it is slightly lower than the $\mathrm{D}^{\prime}$ fast values previously reported, it remains in the same order of magnitude, suggesting the potential accuracy of those previous $\mathrm{D}_{\text {fast }}^{\prime}$ values.

Table 2. Reported values of tri-exponential parameters in healthy liver by studies.

\begin{tabular}{|c|c|c|c|c|c|c|}
\hline Authors, Year & $\mathrm{D}_{\text {Vfast }}^{\prime}$ & $\mathbf{D}_{\text {fast }}^{\prime}$ & $\mathbf{D}_{\text {slow }}^{\prime}$ & $F_{\text {Vfast }}^{\prime}$ & $F_{\text {fast }}^{\prime}$ & $\mathbf{F}_{\text {slow }}^{\prime}$ \\
\hline Cercueil et al., $2015^{\text {a }}$ [22] & 391.96 & 19.54 & 1.23 & 17.1 & 17.6 & 65.3 \\
\hline Cercueil et al., $2015^{\text {b }}$ [22] & 404.00 & 26.50 & 1.35 & 13.5 & 13.7 & 72.7 \\
\hline Kuai et al., 2017 [20] & 386.25 & 19.32 & 1.21 & 17 & 17 & 66 \\
\hline Wurnig et al., 2018 [23] & 270 & 43.8 & 1.26 & 13.4 & 7.8 & 73.8 \\
\hline Chevallier et al., $2019^{\text {c }}$ [24] & 448.8 & 15.4 & 0.98 & 11.7 & 11.7 & 76.6 \\
\hline Chevallier et al., 2019 d [24] & 1911.2 & 16.1 & 0.98 & 11.7 & 11.9 & 76.4 \\
\hline Riexinger et al., $2019^{\text {e }}$ [25] & 2453 & 81.3 & 1.22 & 15.2 & 16.1 & $68.7 *$ \\
\hline Riexinger et al., $2019^{\mathrm{f}}$ [25] & 2333 & 65.9 & 1.00 & 15.9 & 17.4 & $69.7 *$ \\
\hline Riexinger et al., $2021^{g}$ [26] & 500 & 16 & 1.1 & 10.8 & 13.1 & $76.1 *$ \\
\hline
\end{tabular}

a pilot study; ${ }^{\mathrm{b}}$ validation study; ${ }^{\mathrm{c}}$ results from averaged data from 50 scans with segmented fitting method; ${ }^{\mathrm{d}}$ mean parameter values of the 50 scans calculated one by one with segmented fitting method; ${ }^{\mathrm{e}}$ results at $1.5 \mathrm{~T}$; ${ }^{\mathrm{f}}$ results at $3 \mathrm{~T} ; \mathrm{g}$ in vivo measurement. ${ }^{*} \mathrm{~F}_{\text {slow }}^{\prime}$ calculated from reported $\mathrm{F}_{\text {Vfast }}^{\prime}$ and $\mathrm{F}_{\text {fast }}^{\prime}$ as $\mathrm{F}_{\text {Vfast }}^{\prime}+\mathrm{F}_{\text {fast }}^{\prime}+\mathrm{F}_{\text {slow }}^{\prime}=100 \%$; $\mathrm{D}_{\text {vfast, }}^{\prime} \mathrm{D}_{\text {fast }}^{\prime}$ and $\mathrm{D}_{\text {slow }}^{\prime}$ in $10^{-3} \mathrm{~mm}^{2} / \mathrm{s} ; \mathrm{F}_{\text {vfast }}^{\prime} \mathrm{F}_{\text {fast }}^{\prime}$ and $\mathrm{F}_{\text {slow }}^{\prime}$ in $\%$.

Table 3. Main acquisition parameters for DWI sequence by studies.

\begin{tabular}{|c|c|c|c|c|c|c|}
\hline Authors, Year & $\mathbf{B}_{0}$ & TE & Breathing Management & No. of b-Values & b-Values $\leq 15$ & Highest $b$-Value \\
\hline Cercueil et al., 2015 a [22] & $3 \mathrm{~T}$ & $68 \mathrm{~ms}$ & NET & 11 & $0,5,15$ & 800 \\
\hline Cercueil et al., 2015 b [22] & $3 \mathrm{~T}$ & $67 \mathrm{~ms}$ & NET & 16 & $0,5,10,15$ & 800 \\
\hline Kuai et al., 2017 [20] & $3 \mathrm{~T}$ & $68 \mathrm{~ms}$ & NET & 11 & $0,5,15$ & 800 \\
\hline Wurnig et al., 2018 [23] & $3 \mathrm{~T}$ & $57 \mathrm{~ms}$ & FB & 68 & 0,15 & 1005 \\
\hline Chevallier et al., 2019 [24] & $3 \mathrm{~T}$ & $55 \mathrm{~ms}$ & $\mathrm{RT}^{*}$ & 16 & $0,3,10$ & 800 \\
\hline Riexinger et al., 2019 [25] & $1.5 \mathrm{~T}$ & $100 \mathrm{~ms}$ & FB & 24 & $\begin{array}{c}0.2,0.4,0.7,0.8 \\
1.1,1.7,3,3.8 \\
4.1,4.3,4.4,4.5 \\
4.9,10,15\end{array}$ & 500 \\
\hline Riexinger et al., 2019 [25] & $3 \mathrm{~T}$ & $100 \mathrm{~ms}$ & FB & 24 & $\begin{array}{c}0.2,0.4,0.7,0.8 \\
1.1,1.7,3,3.8 \\
4.1,4.3,4.4,4.5 \\
4.9,10,15\end{array}$ & 500 \\
\hline Riexinger et al., 2021 c [26] & $3 \mathrm{~T}$ & $45 \mathrm{~ms}$ & $\mathrm{RT}$ & 16 & $\begin{array}{c}0,0.3,1,1.2,1.5 \\
3.5,5,6\end{array}$ & 800 \\
\hline
\end{tabular}

${ }^{a}$ pilot study; ${ }^{b}$ validation study; ${ }^{c}$ in vivo study with optimized 16 b-values data set; No, number; NET, navigator-echo-triggering; FB, free breathing; RT, respiratory triggering; $\mathrm{RT}^{*}$, respiratory triggering using an air-filled pressure sensor fixed on the upper abdomen; $b$-value in $\mathrm{s} / \mathrm{mm}^{2}$. 
Lower $\mathrm{D}_{\text {Vfast }}$ and larger $\mathrm{D}_{\text {fast }}$ were found in one study [23]. This can be explained by the lake of very low $b$-value inferior to $b=15 \mathrm{~s} / \mathrm{mm}^{2}$. The contribution to the DWI signal of the very fast compartment of diffusion is indeed very low $[20,22,24]$. It was estimated at $11.7 \%$ and $13.5 \%$ at $\mathrm{b}=0 \mathrm{~s} / \mathrm{mm}^{2}$, before dropping dramatically to $3.4 \%$ at $\mathrm{b}=3 \mathrm{~s} / \mathrm{mm}^{2}$ or $2.09 \%$ at $b=5 \mathrm{~s} / \mathrm{mm}^{2}$, to finally become negligible at $\mathrm{b}=10 \mathrm{~s} / \mathrm{mm}^{2}$ with a contribution to signal of $0.15 \%$ or $0.29 \%$ [22,24]. This highlights the importance of an adequate sampling of the DWI signal decay for very low $b$-values, ranging from $b=0-10 \mathrm{~s} / \mathrm{mm}^{2}$. Indeed, most of the articles that explored the tri-exponential model presented subsampling of the very low $b$-values, with only $0-2 \mathrm{~b}$-values between $\mathrm{b}=0$ and $\mathrm{b}=15 \mathrm{~s} / \mathrm{mm}^{2}$ (Table 3) [20,22-24]. On the contrary, with $15 \mathrm{~b}$-values in the range $\mathrm{b}=0-15 \mathrm{~s} / \mathrm{mm}^{2}$, several very low $\mathrm{b}$-values between $b=0$ and $b=1 \mathrm{~s} / \mathrm{mm}^{2}$ and between $b=1$ and $b=5 \mathrm{~s} / \mathrm{mm}^{2}$, one study found much larger $\mathrm{D}^{\prime}{ }_{\text {Vfast }}$ and $\mathrm{D}_{\text {fast }}$, i.e., 2453 and $81.3 \mathrm{~mm}^{2} / \mathrm{s}$, respectively (Tables 2 and 3) [25]. The authors suggested those larger values could be explained by the smaller minimal $\mathrm{b}$-values used for the acquisitions. However, another recent study aiming to find an optimized b-value distribution for reproducible tri-exponential IVIM in the liver, also included several very low b-values in an optimized b-values data set [26]. Despite this b-values distribution, lower $\mathrm{D}_{\text {Vfast }}^{\prime}$ and $\mathrm{D}_{\text {fast }}^{\prime}$, i.e., 500 and $16 \mathrm{~mm}^{2} / \mathrm{s}$, were found in three volunteers. These last coefficients are much closer to those published in previous studies, particularly $\mathrm{D}_{\text {fast }}^{\prime}[20,22,24]$. The parameter variations between these two studies could be explained by the different slice orientation that has been used for acquisition, sagittal in the first [25], and axial in the second [26]. The presence of different inflow effects secondary to the use of respiratory triggering in one study compared to free breathing in the other could be another explanation. Inclusion of larger vessels within the ROI might have been produced by free breathing.

In the Chevallier et al. study, parameters were calculated individually for the 50 DWI scans of 18 volunteers [24]. In addition to the parameters' estimation based on the individual scans, the measured signals at each b-value from the 50 scans were also additionally averaged together in order to increase the SNR [22,24,31,32]. The averaged signals (total-averaged) were then fitted. The mean $\mathrm{D}_{\text {fast }}$ value obtained from the individual scans was similar to $\mathrm{D}^{\prime}$ fast value calculated from the fit of the total-averaged 50 scans signals. On the contrary, the mean $\mathrm{D}^{\prime}$ Vfast value estimated from the individual scans was much larger than $\mathrm{D}_{\text {Vfast }}^{\prime}$ calculated from the total-averaged data. This underlines the importance of an adequate SNR at very low b-values. In addition, very low b-values range was subsampled in this study (Table 3).

$\mathrm{F}^{\prime}$ slow value appears quite similar between all studies, ranging from $68.7 \%$ to $76.1 \%$, thus the fraction of the perfusional components $\left(\mathrm{F}_{\text {Vfast }}^{\prime}+\mathrm{F}_{\text {fast }}^{\prime}\right)$ is also quite similar. Since $\mathrm{F}_{\text {Vfast }}^{\prime}+\mathrm{F}_{\text {fast }}^{\prime}$ is similar to PF and $\mathrm{F}_{\text {slow }}^{\prime}=1-\left(\mathrm{F}^{\prime}\right.$ Vfast $\left.+\mathrm{F}_{\text {fast }}^{\prime}\right)$, the difference in $\mathrm{F}_{\text {slow }}$ between studies can be partially explained by the different TE that were used (Tables 2 and 3). Overall, both perfusion fractions, $\mathrm{F}^{\prime}$ Vfast and $\mathrm{F}^{\prime}$ fast are very close to each other.

\section{5. b-Value Distribution for Tri-Exponential Model}

As it has been discussed previously for the IVIM bi-exponential model, the choice of an optimal b-values distribution is crucial for accurate parameters estimation and to reduce the fit uncertainty $[9,33]$. An adequate sampling of $b$-value related to each diffusion compartment is essential. For b-values ranges $0-10$ or $0-15 \mathrm{~s} / \mathrm{mm}^{2}$, the three compartments contribute to the DWI signal $[20,22,24]$. For $10-15 \leq b \leq 100-200 \mathrm{~s} / \mathrm{mm}^{2}$, the contribution to signal of the very fast diffusion compartment becomes negligible, while the fast and the slow diffusion compartments contribute to the DWI signal. For b $\geq 100-200 \mathrm{~s} / \mathrm{mm}^{2}$, only the slow diffusion compartment contributes to the signal. Therefore, for a b-values set, we can hypothesize that the number of b-values $b \leq 10-15 \mathrm{~s} / \mathrm{mm}^{2}$ should be the largest, followed by the number of b-values $10-15 \mathrm{~s} / \mathrm{mm}^{2} \leq \mathrm{b} \leq 100-200 \mathrm{~s} / \mathrm{mm}^{2}$, with the number of $b$-values $b \geq 100-200 \mathrm{~s} / \mathrm{mm}^{2}$ being the smallest. An optimized b-values set, including numerous very low b-values, has been proposed and the acquisition of a minimum of $16 \mathrm{~b}$-values is recommended [26]. In addition, regarding the very low contribution to the 
signal of the very fast compartment, and to a lower extent the contribution of the fast compartment, increasing the number of excitations for very low b-values seems necessary.

\subsection{Effects of the $B_{0}$ Field Strength and the Time of Echo on Tri-Exponential IVIM Parameters}

Effects of the $B_{0}$ field strength on IVIM parameters has been previously reviewed [9]. The parameters $D_{\text {slow }}$ and PF show, respectively, a decrease and an increase with increasing $\mathrm{B}_{0}$ strength [9]. Dependency of the tri-exponential parameters on the magnetic field $\mathrm{B}_{0}$ has been recently studied [25]. With 20 volunteers scanned at $1.5 \mathrm{~T}$ and $3 \mathrm{~T}$ with $24 \mathrm{~b}$-values, the median of $\mathrm{D}_{\text {Vfast }}^{\prime}$ and $\mathrm{D}_{\text {fast }}^{\prime}$ decreased slightly with increased field strength. In contrast, a significant dependency of $\mathrm{D}_{\text {fast }}$ on $\mathrm{B}_{0}$ was found. Nevertheless, dependence of $\mathrm{D}^{\prime}{ }_{\mathrm{Vfast}}$ and $\mathrm{D}_{\text {fast }}^{\prime}$ on $\mathrm{B}_{0}$ could have not been detected because of the high fit uncertainty. In addition, no significant dependency was found on $\mathrm{B}_{0}$ for the fraction parameters, $\mathrm{F}^{\prime}{ }_{\mathrm{Vfast}}, \mathrm{F}^{\prime}$ fast and $\mathrm{F}_{\text {slow }}$. Consistent with literature, $\mathrm{D}_{\text {slow }}$ showed decrease with increasing field strength [9].

Blood and liver tissue present distinct T2 values. The T2 of liver tissue is significantly shorter than the T2 of blood. It has been shown that there is a dependency of PF on the TE, with significant increase of PF when TE is prolonged [32]. Therefore, an increase of $\mathrm{F}^{\prime}{ }_{\text {Vfast }}$ and/or $\mathrm{F}_{\text {fast }}$ and a decrease of $\mathrm{F}_{\text {slow }}$ are expected with increasing TE. This is the trend that we can observe in Tables 2 and 3. A short TE value of $50-70 \mathrm{~ms}$ is generally used in IVIM studies. The use of shorter or longer TE could thus produce discrepancy between studies.

\subsection{Origins of the Fast and Very Fast Compartments of Diffusion in Liver}

The origins of the two perfusion components of diffusion remain not fully understood. The hepatic perfusion is indeed complex. The liver is irrigated by a unique dualblood supply with $75-80 \%$ of hepatic flow coming from portal vein and $20-25 \%$ from hepatic artery $[56,57]$. It contains several vessel types, such as arteries/arterioles, portal veins/venules, hepatic veins/venules, and sinusoid capillaries. In addition, the sinusoid capillaries present zonal gradients of blood flow velocity [58]. Various regimes of blood flow can also be present in vessels [30,59]. An admixture of various perfusion components in liver parenchyma has already been suggested and referred to as the multipleperfusion-components theory [29]. Regarding the coefficient values of very fast and fast compartments, it has been hypothesized that the fast compartment reflects microperfusion effects, whereas the very rapid flowing spins of the very fast compartment are probably located in larger vessels (arterioles and/or portal venules and/or hepatic venules) [22] Regarding the contributions to the signal of the diffusion compartments and the diffusion coefficients values that Wurnig et al. found in their study, the authors suggested that the fast and very fast diffusion compartments might be interpreted as portal and arterial blood pools [23]. However, the ratio $\mathrm{F}^{\prime}{ }_{\text {Vfast }} / \mathrm{F}^{\prime}$ fast has been compared to the estimated relative signal contribution of arterial and venous blood $\left(\mathrm{S}_{\mathrm{A} / \mathrm{V}}\right)$ based on the T2 decay [25]. As $\mathrm{F}^{\prime}$ Vfast $/ \mathrm{F}_{\text {fast }}^{\prime}$ did not show the field dependence of $\mathrm{S}_{\mathrm{A} / \mathrm{V}}$, it seems unlikely that $\mathrm{F}^{\prime}$ Vfast and $\mathrm{F}^{\prime}$ fast represent arterial perfusion and portal venous blood compartments [25]. The authors suggested that the tri-exponential "model" should be rather regarded as a tri-exponential "representation" and that the tri-exponential behavior originates from a distribution of flow velocities due to the presence of different compartments and different vessel sizes [25,60].

Since the slow compartment of diffusion is related to intracellular molecular diffusion [16], faster components of diffusion are related to extracellular moving spin. The extracellular space includes vascular and interstitial compartments. Moreover, spins' velocities between the three observed diffusion compartments present a magnitude ratio of about 10 to 30, and even higher regarding D' $_{\text {Vfast }}$ values in some studies. This large difference in velocities suggests that three very different anatomical compartments contribute to the DWI signal. In addition, the liver presents an important interstitial compartment, called the space of Disse, in which moving spins are likely to contribute to the DWI signal. Therefore, we can hypothesize that the very fast component of diffusion is associated with microcirculation, whereas the fast component of diffusion is linked to moving spins within 
the interstitial compartment. Further studies are required to determine the origins of the perfusion components of diffusion.

\subsection{Limitations of the Tri-Exponential Model}

The tri-exponential model demonstrates high fit uncertainty [24,25]. The low SNR of DWI imaging and the low contribution to signal of the fastest compartments of diffusion can partially explain this instability. With an artificial increase of the SNR by averaging the data of several subjects, the fit uncertainty can be reduced with lower SD for parameters [22]. However, these SDs remain high for the two fastest diffusion compartments [22]. Perfusion related parameters, $\mathrm{D}^{\prime}{ }_{\text {Vfast }}, \mathrm{D}_{\text {fast }}^{\prime}, \mathrm{F}_{\text {Vfast }}^{\prime}, \mathrm{F}_{\text {fast }}^{\prime}$ demonstrate even worse stability at individual level [24]. It has been reported that an increased number of b-values results in a more precise estimation of the parameters $[26,43,61]$. As discussed previously, it is also crucial to include enough very low $b$-values in the $b$-values distribution. However, extensive $b$-values images require long acquisition time that might not be applicable for daily clinical applications. In addition, some MRI platforms present fixed b-values or increments, thus not allowing the selection of an optimal b-value distribution for tri-exponential IVIM. Moreover, the generation of parametric IVIM maps, which might be preferred for clinical application, would even be more challenging than the ROI analysis method that has been performed.

The assessment of the very fast compartment of diffusion is challenging. Wang et al. investigated a combined use of bi-exponential IVIM parameters for liver fibrosis evaluation [12]. Interestingly, only b-values $\geq 10 \mathrm{~s} / \mathrm{mm}^{2}$ images have been acquired. As the contribution to signal of the very fast compartment of diffusion becomes negligible at $\mathrm{b}=10 \mathrm{~s} / \mathrm{mm}^{2}$, the acquisition of only $\mathrm{b}$-values $\geq 10 \mathrm{~s} / \mathrm{mm}^{2}$ reduces the tri-compartmental model to a bi-compartmental model. Using a three-dimensional tool that included all three bi-exponential IVIM parameters, results were particularly compelling to differentiate patients without liver fibrosis and patients with F1 or F2 fibrosis (AUC, respectively, 0.986 and 1) in cases of viral hepatitis. Therefore, the assessment of the very fast compartment of diffusion may not be essential for liver disease evaluation [12]. Moreover, using the bi-exponential model for $\mathrm{b}$-values $\geq 10 \mathrm{~s} / \mathrm{mm}^{2}$ might reduce the fit uncertainty. Indeed, less parameters require to be calculated and the signal contamination of the very fast compartment is negligible for $b \geq 10 \mathrm{~s} / \mathrm{mm}^{2}$. Other authors proposed the removal of voxels within the ROI presenting tri-exponential decay [62]. To this end, these voxels were identified on an ADC image created from $b=0$ and $b=10 \mathrm{~s} / \mathrm{mm}^{2}$. Similarly, Gambarota et al. proposed to first detect the compartment number by using the non-negative least squares method, and then to process the fit without the $b=0$ data point in pixels presenting a tri-exponential decay [63]. However, no b-values between $b=0$ and $b=10 \mathrm{~s} / \mathrm{mm}^{2}$ were included in these last two studies. If several very low $b$-values $\leq 10 \mathrm{~s} / \mathrm{mm}^{2}$ images are acquired, we believe that the majority of voxels will present a tri-exponential decay (Figure 4) [64].

If the bi-exponential model is processed with only nonzero $b$-values, $b=0$ and very low b-values images can still be useful. Recently, the concept of diffusion-derived vessel density (DDVD) parameter has been proposed to address the initial fast signal decay [65-67]. This concept proposed that the relationship between liver DWI signal and b-value can be separated into two parts: part- 1 is the signal difference between the $b=0 \mathrm{~s} / \mathrm{mm}^{2}$ image and the first very low $b$-value image (usually $b=1$ or $2 \mathrm{~s} / \mathrm{mm}^{2}$ image); the rest is part-2 and fitted with a bi-exponential decay model. On DWI images, blood vessels show a high signal on the unweighted DWI images and low signal with the application of diffusion gradient, even at very low b-value (e.g., $1-15 \mathrm{~s} / \mathrm{mm}^{2}$ ). Therefore, the difference between these unweighted and weighted images would reflect the extent of tissue vessel density (referred to as DDVD) [65-67]. DDVD analysis could represent a potential biomarker for detecting liver fibrosis. Moreover, the combination of DDVD and bi-exponential IVIM parameters has been shown to improve the separation of fibrotic and nonfibrotic livers [65]. 


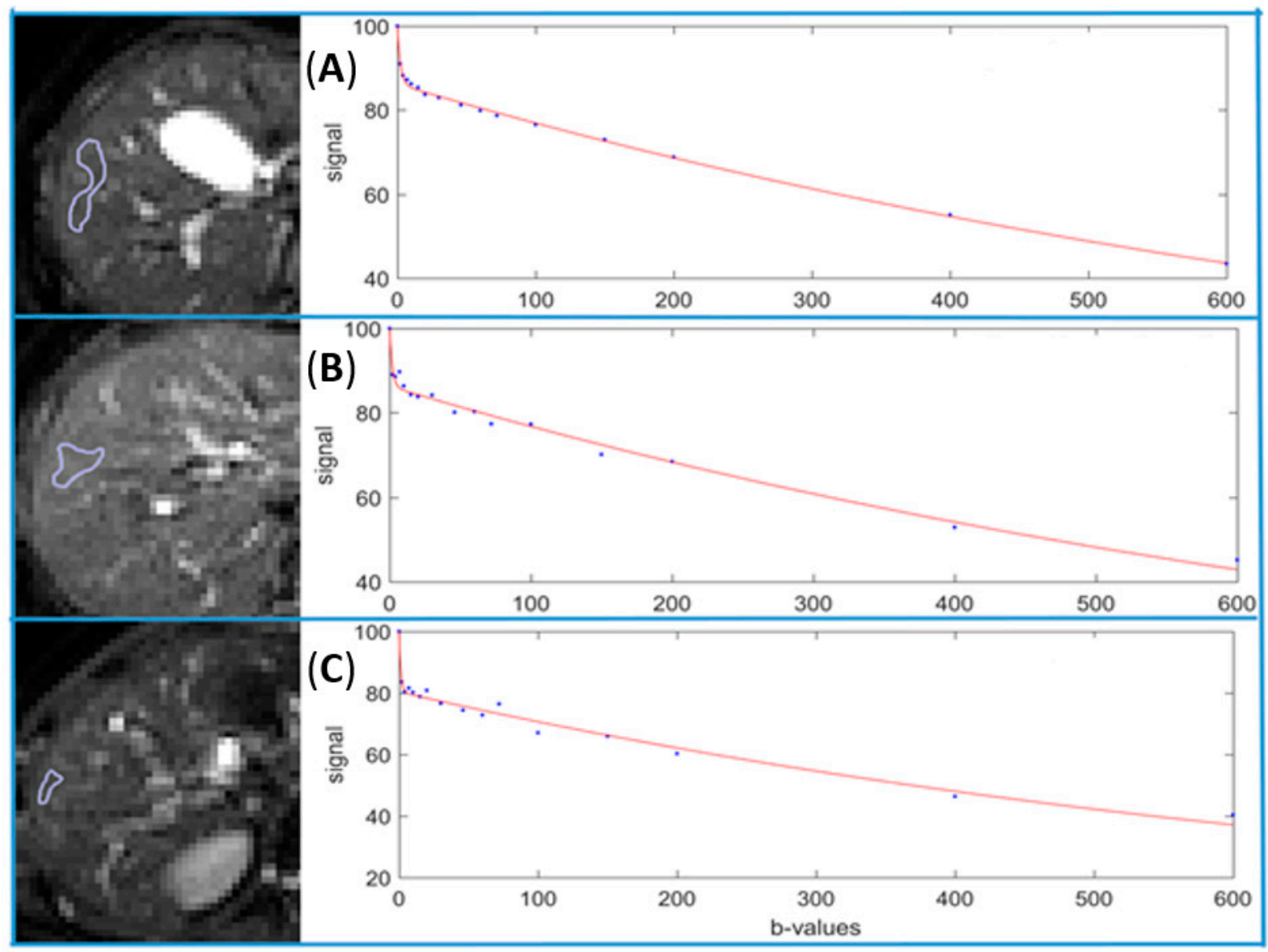

Figure 4. Bi-exponential full fitting curves of three portions of liver parenchyma from three healthy livers. On $b=0$ images, small ROIs are drawn on three different location on the liver parenchyma excluding bright pixels which would contain a 'visible' vessel (A-C). The b-value distribution is $0,2,4,7,10,15,20,30,46,60,72,100,150,200,400,600 \mathrm{~s} / \mathrm{mm}^{2}$, and fitting starts from $b=0$ image. Note although the ROIs do not contain a visible vessel, a steep drop of signal from $b=0$ to $\mathrm{b}=2 \mathrm{~s} / \mathrm{mm}^{2}$ can still be seen for $(\mathbf{A}-\mathbf{C})$, this would be caused by subpixel microvessels which show high signal on $b=0$ image while low signal on $\mathrm{b}=2$ image.

More than two perfusion components of diffusion may also exist and would require another model $[20,29,30]$. However, it is unlikely that other fast diffusion compartments may be assessed with the present hardware. Moreover, an additional slow component of diffusion has been explored but requires higher b-values to be assessed $[61,68]$. The addition of another diffusion compartment to the proposed tri-exponential model would make the equation more complex and decrease the fit certainty.

\subsection{Clinical Applications}

To our knowledge, this tri-exponential model with two fast components of diffusion has not been tested for the assessment of diffuse liver disease or liver lesion. The adequacy of the tri-exponential model in diseased settings requires further investigation.

However, the tri-exponential model has been tested for the assessment of renal masses [69]. In this study, parameters obtained from diffusion tensor imaging parameters, IVM bi-exponential model $\left(\mathrm{D}_{\text {slow }}, \mathrm{PF}\right)$ and tri-exponential model $\left(\mathrm{D}_{\text {slow }}^{\prime}, \mathrm{F}_{\text {slow }}^{\prime}, \mathrm{F}_{\text {fast }}^{\prime}\right.$, $\mathrm{F}^{\prime}{ }_{\text {Vfast }}$ ) were compared for the characterization of renal lesions in 16 patients. Histological examination after surgery allowed the determination of tumor type and specificities. Parameters values were found to be representative of some histological features. Both parameters PF and $\mathrm{F}^{\prime}$ ffast seemed to correlate to vascularization. However, the triexponential model provided additional information over the bi-exponential model, since only the tri-exponential parameters $\mathrm{F}^{\prime}$ fast and $\mathrm{F}^{\prime}{ }_{\text {Vfast }}$ demonstrated significant differences 
between different tissues whereas the bi-exponential parameter PF did not [69]. These results highlight the potential improvement in tumor assessment that is provided by the tri-exponential model.

\section{Conclusions}

This review demonstrates that there is concrete evidence of the presence of another fast component of diffusion in the healthy liver. The tri-exponential decay model better fits the recorded DWI signal than the classic bi-exponential IVIM model. However, tri-exponential model application remains challenging. In typical clinical settings, the parameters related to the very fast compartment and fast compartment of diffusion show apparent instability with high fit uncertainty. An extensive DWI-imaging protocol including a high number of very low b-values is required. Technical improvements and more robust fitting methods might allow a more accurate estimate of the tri-exponential IVIM parameters. Further studies are required to explore the performance of the tri-exponential IVIM model in the assessment of liver diseases. New regression models, which allow a better assessment of the microcirculation in the liver, are desired.

Author Contributions: Conceptualization, O.C. and R.L.; methodology, O.C., Y.X.J.W.; software, K.G. and J.P.; validation, O.C., J.-P.C. and R.L.; formal analysis, J.P.; investigation, O.C., J.P. and R.L.; resources, K.G.; data curation, K.G.; writing-original draft preparation, O.C., Y.X.J.W., J.-P.C. and R.L.; writing-review and editing, O.C., Y.X.J.W., J.-P.C. and R.L.; visualization, R.L.; supervision, Y.X.J.W. and R.L.; project administration, R.L.; funding acquisition, R.L. All authors have read and agreed to the published version of the manuscript.

Funding: This research received no external funding.

Institutional Review Board Statement: Not applicable.

Informed Consent Statement: Not applicable.

Data Availability Statement: The data presented in this study are available on request from the corresponding author. The data are not publicly available due to identity reasons.

Conflicts of Interest: The authors declare no conflict of interest.

\section{References}

1. Coenegrachts, K.; Delanote, J.; Ter Beek, L.; Haspeslagh, M.; Bipat, S.; Stoker, J.; Van Kerkhove, F.; Steyaert, L.; Rigauts, H.; Casselman, J.W. Improved focal liver lesion detection: Comparison of single-shot diffusion-weighted echoplanar and single-shot T2 weighted turbo spin echo techniques. Br. J. Radiol. 2007, 80, 524-531. [CrossRef]

2. Koh, D.M.; Brown, G.; Riddell, A.M.; Scurr, E.; Collins, D.J.; Allen, S.D.; Chau, I.; Cunningham, D.; deSouza, N.M.; Leach, M.O.; et al. Detection of colorectal hepatic metastases using MnDPDP MR imaging and diffusion-weighted imaging (DWI) alone and in combination. Eur. Radiol. 2008, 18, 903-910. [CrossRef]

3. Colagrande, S.; Castellani, A.; Nardi, C.; Lorini, C.; Calistri, L.; Filippone, A. The role of diffusion-weighted imaging in the detection of hepatic metastases from colorectal cancer: A comparison with unenhanced and Gd-EOB-DTPA enhanced MRI. Eur. J. Radiol. 2016, 85, 1027-1034. [CrossRef]

4. Vilgrain, V.; Esvan, M.; Ronot, M.; Caumont-Prim, A.; Aubé, C.; Chatellier, G. A meta-analysis of diffusion-weighted and gadoxetic acid-enhanced MR imaging for the detection of liver metastases. Eur. Radiol. 2016, 26, 4595-4615. [CrossRef]

5. Taouli, B.; Chouli, M.; Martin, A.J.; Qayyum, A.; Coakley, F.V.; Vilgrain, V. Chronic hepatitis: Role of diffusion-weighted imaging and diffusion tensor imaging for the diagnosis of liver fibrosis and inflammation. J. Magn. Reson. Imaging 2008, 28, 89-95. [CrossRef]

6. Petitclerc, L.; Sebastiani, G.; Gilbert, G.; Cloutier, G.; Tang, A. Liver fibrosis: Review of current imaging and MRI quantification techniques. J. Magn. Reson. Imaging 2017, 45, 1276-1295. [CrossRef]

7. Luciani, A.; Vignaud, A.; Cavet, M.; Nhieu, J.T.V.; Mallat, A.; Ruel, L.; Laurent, A.; Deux, J.F.; Brugieres, P.; Rahmouni, A. Liver cirrhosis: Intravoxel incoherent motion MR imaging-Pilot study. Radiology 2008, 249, 891-899. [CrossRef]

8. Palmucci, S.; Cappello, G.; Attinà, G.; Fuccio Sanzà, G.; Foti, P.V.; Ettorre, G.C.; Milone, P. Diffusion-weighted MRI for the assessment of liver fibrosis: Principles and applications. BioMed. Res. Int. 2015, 2015, 874201. [CrossRef]

9. Li, Y.T.; Cercueil, J.P.; Yuan, J.; Chen, W.; Loffroy, R.; Wáng, Y.X.J. Liver intravoxel incoherent motion (IVIM) magnetic resonance imaging: A comprehensive review of published data on normal values and applications for fibrosis and tumor evaluation. Quant. Imaging Med. Surg. 2017, 7, 59-78. [CrossRef] 
10. Li, T.; Che-Nordin, N.; Wáng, Y.X.J.; Rong, P.F.; Qiu, S.W.; Zhang, S.W.; Zhang, P.; Jiang, Y.F.; Chevallier, O.; Zhao, F.; et al. Intravoxel incoherent motion derived liver perfusion/diffusion readouts can be reliable biomarker for the detection of viral hepatitis B induced liver fibrosis. Quant. Imaging Med. Surg. 2019, 9, 371-385. [CrossRef] [PubMed]

11. Huang, H.; Che-Nordin, N.; Wang, L.F.; Xiao, B.H.; Chevallier, O.; Yun, Y.X.; Guo, S.W.; Wáng, Y.X.J. High performance of intravoxel incoherent motion diffusion MRI in detecting viral hepatitis-b induced liver fibrosis. Ann. Transl. Med. $2019,7,39$. [CrossRef]

12. Wáng, Y.X.J.; Deng, M.; Li, Y.T.; Huang, H.; Leung, J.C.S.; Chen, W.; Lu, P.X. A Combined use of intravoxel incoherent motion MRI parameters can differentiate early-stage hepatitis-b fibrotic livers from healthy livers. SLAS Technol. 2018, 23, 259-268. [CrossRef]

13. Gheorghe, G.; Stoian, A.P.; Gaman, M.A.; Socea, B.; Neagu, T.P.; Stanescu, A.M.A.; Bratu, O.G.; Mischianu, D.L.D.; Suceveanu, A.I.; Diaconu, C.C. The benefits and risks of antioxidant treatment in liver diseases. Rev. Chim. 2019, 70, 651-655. [CrossRef]

14. Koh, D.M.; Collins, D.J. Diffusion-weighted MRI in the body: Applications and challenges in oncology. AJR. Am. J. Roentgenol. 2007, 188, 1622-1635. [CrossRef]

15. Shah, B.; Anderson, S.W.; Scalera, J.; Jara, H.; Soto, J.A. Quantitative MR imaging: Physical principles and sequence design in abdominal imaging. Radiographics 2011, 31, 867-880. [CrossRef]

16. Le Bihan, D.; Breton, E.; Lallemand, D.; Grenier, P.; Cabanis, E.; Laval-Jeantet, M. MR imaging of intravoxel incoherent motions: Application to diffusion and perfusion in neurologic disorders. Radiology 1986, 161, 401-407. [CrossRef]

17. Le Bihan, D.; Breton, E.; Lallemand, D.; Aubin, M.L.; Vignaud, J.; Laval-Jeantet, M. Separation of diffusion and perfusion in intravoxel incoherent motion MR imaging. Radiology 1988, 168, 497-505. [CrossRef]

18. Turner, R.; Le Bihan, D.; Maier, J.; Vavrek, R.; Hedges, L.K.; Pekar, J. Echo-planar imaging of intravoxel incoherent motion. Radiology 1990, 177, 407-414. [CrossRef]

19. Chow, A.M.; Gao, D.S.; Fan, S.J.; Qiao, Z.; Lee, F.Y.; Yang, J.; Man, K.; Wu, E.X. Liver fibrosis: An intravoxel incoherent motion (IVIM) study. J. Magn. Reson. Imaging 2012, 36, 159-167. [CrossRef]

20. Kuai, Z.X.; Liu, W.Y.; Zhu, Y.M. Effect of multiple perfusion components on pseudo-diffusion coefficient in intravoxel incoherent motion imaging. Phys. Med. Biol. 2017, 62, 8197-8209. [CrossRef]

21. Ohtani, O.; Ohtani, Y. Lymph circulation in the liver. Anat. Rec. 2008, 291, 643-652. [CrossRef] [PubMed]

22. Cercueil, J.P.; Petit, J.M.; Nougaret, S.; Soyer, P.; Fohlen, A.; Pierredon-Foulongne, M.A.; Schembri, V.; Delhom, E.; Schmidt, S.; Denys, A.; et al. Intravoxel incoherent motion diffusion-weighted imaging in the liver: Comparison of mono-, bi- and tri-exponential modelling at 3.0-T. Eur. Radiol. 2015, 25, 1541-1550. [CrossRef] [PubMed]

23. Wurnig, M.C.; Germann, M.; Boss, A. Is there evidence for more than two diffusion components in abdominal organs?-A magnetic resonance imaging study in healthy volunteers. NMR Biomed. 2018, 31. [CrossRef]

24. Chevallier, O.; Zhou, N.; Cercueil, J.P.; He, J.; Loffroy, R.; Wáng, Y.X.J. Comparison of tri-exponential decay versus bi-exponential decay and full fitting versus segmented fitting for modeling liver intravoxel incoherent motion diffusion MRI. NMR Biomed. 2019, 32. [CrossRef]

25. Riexinger, A.J.; Martin, J.; Rauh, S.; Wetscherek, A.; Pistel, M.; Kuder, T.A.; Nagel, A.M.; Uder, M.; Hensel, B.; Müller, L.; et al. On the field strength dependence of bi- and triexponential intravoxel incoherent motion (IVIM) parameters in the liver. J. Magn. Reson. Imaging 2019, 50, 1883-1892. [CrossRef]

26. Riexinger, A.; Martin, J.; Wetscherek, A.; Kuder, T.A.; Uder, M.; Hensel, B.; Laun, F.B. An optimized b-value distribution for triexponential intravoxel incoherent motion (IVIM) in the liver. Magn. Reson. Med. 2021, 85, 2095-2108. [CrossRef]

27. Cohen, A.D.; Schieke, M.C.; Hohenwalter, M.D.; Schmainda, K.M. The effect of low b-values on the intravoxel incoherent motion derived pseudodiffusion parameter in liver. Magn. Reson. Med. 2015, 73, 306-311. [CrossRef]

28. Maki, J.H.; MacFall, J.R.; Johnson, G.A. The use of gradient flow compensation to separate diffusion and microcirculatory flow in MRI. Magn. Reson. Med. 1991, 17, 95-107. [CrossRef]

29. Moteki, T.; Horikoshi, H. Evaluation of noncirrhotic hepatic parenchyma with and without significant portal vein stenosis using diffusion-weighted echo-planar MR on the basis of multiple-perfusion-components theory. Magn. Reson. Imaging 2011, 29, 64-73. [CrossRef]

30. Kuai, Z.X.; Liu, W.Y.; Zhang, Y.L.; Zhu, Y.M. Generalization of intravoxel incoherent motion model by introducing the notion of continuous pseudodiffusion variable. Magn. Reson. Med. 2016, 76, 1594-1603. [CrossRef]

31. Delattre, B.M.A.; Viallon, M.; Wei, H.; Zhu, Y.M.; Feiweier, T.; Pai, V.M.; Wen, H.; Croisille, P. In vivo cardiac diffusion-weighted magnetic resonance imaging: Quantification of normal perfusion and diffusion coefficients with intravoxel incoherent motion imaging. Investig. Radiol. 2012, 47, 662-670. [CrossRef]

32. Lemke, A.; Laun, F.B.; Simon, D.; Stieltjes, B.; Schad, L.R. An in vivo verification of the intravoxel incoherent motion effect in diffusion-weighted imaging of the abdomen. Magn. Reson. Med. 2010, 64, 1580-1585. [CrossRef]

33. Lemke, A.; Stieltjes, B.; Schad, L.R.; Laun, F.B. Toward an optimal distribution of b values for intravoxel incoherent motion imaging. Magn. Reson. Imaging 2011, 29, 766-776. [CrossRef]

34. Van Baalen, S.; Leemans, A.; Dik, P.; Lilien, M.R.; Ten Haken, B.; Froeling, M. Intravoxel incoherent motion modeling in the kidneys: Comparison of mono-, bi-, and triexponential fit. J. Magn. Reson. Imaging 2017, 46, 228-239. [CrossRef]

35. Graham, S.J.; Bronskill, M.J. MR measurement of relative water content and multicomponent T2 relaxation in human breast. Magn. Reson. Med. 1996, 35, 706-715. [CrossRef] 
36. Whittall, K.P.; MacKay, A.L.; Graeb, D.A.; Nugent, R.A.; Li, D.K.; Paty, D.W. In vivo measurement of T2 distributions and water contents in normal human brain. Magn. Reson. Med. 1997, 37, 34-43. [CrossRef] [PubMed]

37. Chevallier, O.; Zhou, N.; He, J.; Loffroy, R.; Wáng, Y.X.J. Removal of evidential motion-contaminated and poorly fitted image data improves IVIM diffusion MRI parameter scan-rescan reproducibility. Acta Radiol. 2018, 59, 1157-1167. [CrossRef]

38. Motulsky, H.J.; Christopoulos, A. Fitting Models to Biological Data Using Linear and Non-Linear Regression: A Practical Guide to Curve Fitting; Oxford University Press: London, UK, 2004.

39. van der Bel, R.; Gurney-Champion, O.J.; Froeling, M.; Stroes, E.S.G.; Nederveen, A.J.; Krediet, C.T.P. A Tri-exponential model for intravoxel incoherent motion analysis of the human kidney: In silico and during pharmacological renal perfusion modulation. Eur. J. Radiol. 2017, 91, 168-174. [CrossRef] [PubMed]

40. Park, H.J.; Sung, Y.S.; Lee, S.S.; Lee, Y.; Cheong, H.; Kim, Y.J.; Lee, M.-G. Intravoxel incoherent motion diffusion-weighted MRI of the abdomen: The effect of fitting algorithms on the accuracy and reliability of the parameters. J. Magn. Reson. Imaging 2017, 45, 1637-1647. [CrossRef] [PubMed]

41. Guiu, B.; Petit, J.M.; Capitan, V.; Aho, S.; Masson, D.; Lefevre, P.H.; Favelier, S.; Loffroy, R.; Vergès, B.; Hillon, P.; et al. Intravoxel incoherent motion diffusion-weighted imaging in nonalcoholic fatty liver disease: A 3.0-T MR study. Radiology 2012, 265, 96-103. [CrossRef]

42. Wurnig, M.C.; Donati, O.F.; Ulbrich, E.; Filli, L.; Kenkel, D.; Thoeny, H.C.; Boss, A. Systematic analysis of the intravoxel incoherent motion threshold separating perfusion and diffusion effects: Proposal of a standardized algorithm. Magn. Reson. Med. 2015, 74, 1414-1422. [CrossRef]

43. Patel, J.; Sigmund, E.E.; Rusinek, H.; Oei, M.; Babb, J.S.; Taouli, B. Diagnosis of cirrhosis with intravoxel incoherent motion diffusion MRI and dynamic contrast-enhanced MRI alone and in combination: Preliminary experience. J. Magn. Reson. Imaging 2010, 31, 589-600. [CrossRef] [PubMed]

44. Yuan, J.; Wong, O.L.; Lo, G.G.; Chan, H.H.L.; Wong, T.T.; Cheung, P.S.Y. Statistical assessment of bi-exponential diffusion weighted imaging signal characteristics induced by intravoxel incoherent motion in malignant breast tumors. Quant. Imaging Med. Surg. 2016, 6, 418-429. [CrossRef]

45. Li, Y.T.; Huang, H.; Zhuo, Z.; Lu, P.X.; Chen, W.; Wáng, Y.X.J. Bi-phase age-related brain gray matter magnetic resonance T1 $\rho$ relaxation time change in adults. Magn. Reson. Imaging 2017, 39, 200-205. [CrossRef]

46. Freiman, M.; Perez-Rossello, J.M.; Callahan, M.J.; Voss, S.D.; Ecklund, K.; Mulkern, R.V.; Warfield, S.K. Reliable estimation of incoherent motion parametric maps from diffusion-weighted MRI using fusion bootstrap moves. Med. Image Anal. 2013, 17, 325-336. [CrossRef] [PubMed]

47. Kurugol, S.; Freiman, M.; Afacan, O.; Perez-Rossello, J.M.; Callahan, M.J.; Warfield, S.K. Spatially-constrained probability distribution model of incoherent motion (SPIM) for abdominal diffusion-weighted MRI. Med. Image Anal. 2016, 32, 173-183. [CrossRef]

48. Barbieri, S.; Donati, O.F.; Froehlich, J.M.; Thoeny, H.C. Impact of the calculation algorithm on biexponential fitting of diffusionweighted MRI in upper abdominal organs. Magn. Reson. Med. 2016, 75, 2175-2184. [CrossRef]

49. Neil, J.J.; Bretthorst, G.L. On the use of Bayesian probability theory for analysis of exponential decay data: An example taken from intravoxel incoherent motion experiments. Magn. Reson. Med. 1993, 29, 642-647. [CrossRef]

50. Orton, M.R.; Collins, D.J.; Koh, D.M.; Leach, M.O. Improved intravoxel incoherent motion analysis of diffusion weighted imaging by data driven Bayesian modeling. Magn. Reson. Med. 2014, 71, 411-420. [CrossRef]

51. Lanzarone, E.; Mastropietro, A.; Scalco, E.; Vidiri, A.; Rizzo, G. A novel Bayesian approach with conditional autoregressive specification for intravoxel incoherent motion diffusion-weighted MRI. NMR Biomed. 2020, 33, e4201. [CrossRef] [PubMed]

52. Bertleff, M.; Domsch, S.; Weingärtner, S.; Zapp, J.; O’Brien, K.; Barth, M.; Schad, L.R. Diffusion parameter mapping with the combined intravoxel incoherent motion and kurtosis model using artificial neural networks at 3 T. NMR Biomed. 2017, 30. [CrossRef]

53. Barbieri, S.; Gurney-Champion, O.J.; Klaassen, R.; Thoeny, H.C. Deep learning how to fit an intravoxel incoherent motion model to diffusion-weighted MRI. Magn. Reson. Med. 2020, 83, 312-321. [CrossRef] [PubMed]

54. Liu, J.; Gambarota, G.; Shu, H.; Jiang, L.; Leporq, B.; Beuf, O.; Karfoul, A. Efficient sparsity-based algorithm for parameter estimation of the tri-exponential intra voxel incoherent motion (IVIM) model: Application to diffusion-weighted MR imaging in the liver. In Proceedings of the 2017 IEEE 7th International Workshop on Computational Advances in Multi-Sensor Adaptive Processing (CAMSAP), Curaçao, The Netherlands, 10-13 December 2017; pp. 1-5. [CrossRef]

55. Liu, J.; Gambarota, G.; Shu, H.; Jiang, L.; Leporq, B.; Beuf, O.; Karfoul, A. All-in-one approach for constrained all-voxel triexponential IVIM model identification: Application to diffusion-weighted MR imaging in the liver. In Proceedings of the 2018 52nd Asilomar Conference on Signals, Systems, and Computers, Pacific Grove, CA, USA, 28-31 October 2018; pp. $1192-1196$. [CrossRef]

56. Richter, S.; Mücke, I.; Menger, M.D.; Vollmar, B. Impact of intrinsic blood flow regulation in cirrhosis: Maintenance of hepatic arterial buffer response. Am. J. Physiol. Gastrointest. Liver Physiol. 2000, 279, G454-G462. [CrossRef]

57. Vollmar, B.; Menger, M.D. The hepatic microcirculation: Mechanistic contributions and therapeutic targets in liver injury and repair. Physiol. Rev. 2009, 89, 1269-1339. [CrossRef]

58. Komatsu, H.; Koo, A.; Guth, P.H. Leukocyte flow dynamics in the rat liver microcirculation. Microvasc. Res. 1990, 40, 1-13. [CrossRef] 
59. van Tyen, R.; Saloner, D.; Jou, L.D.; Berger, S. MR imaging of flow through tortuous vessels: A numerical simulation. Magn. Reson. Med. 1994, 31, 184-195. [CrossRef]

60. Fournet, G.; Li, J.R.; Cerjanic, A.M.; Sutton, B.P.; Ciobanu, L.; Le Bihan, D. A two-pool model to describe the IVIM cerebral perfusion. J. Cereb. Blood Flow Metab. 2017, 37, 2987-3000. [CrossRef] [PubMed]

61. Hayashi, T.; Miyati, T.; Takahashi, J.; Fukuzawa, K.; Sakai, H.; Tano, M.; Saitoh, S. Diffusion analysis with triexponential function in liver cirrhosis. J. Magn. Reson. Imaging 2013, 38, 148-153. [CrossRef] [PubMed]

62. Gurney-Champion, O.J.; Froeling, M.; Klaassen, R.; Runge, J.H.; Bel, A.; van Laarhoven, H.W.M.; Stoker, J.; Nederveen, A.J. Minimizing the acquisition time for intravoxel incoherent motion magnetic resonance imaging acquisitions in the liver and pancreas. Investig. Radiol. 2016, 51, 211-220. [CrossRef]

63. Gambarota, G.; Hitti, E.; Leporq, B.; Saint-Jalmes, H.; Beuf, O. Eliminating the blood-flow confounding effect in intravoxel incoherent motion (IVIM) using the non-negative least square analysis in liver. Magn. Reson. Med. 2017, 77, 310-317. [CrossRef]

64. Wáng, Y.X.J.; Wang, X.; Wu, P.; Wang, Y.; Chen, W.; Chen, H.; Li, J. Topics on quantitative liver magnetic resonance imaging. Quant. Imaging Med. Surg. 2019, 9, 1840-1890. [CrossRef] [PubMed]

65. Xiao, B.H.; Huang, H.; Wang, L.F.; Qiu, S.W.; Guo, S.W.; Wáng, Y.X.J. Diffusion MRI derived per area vessel density as a surrogate biomarker for detecting viral hepatitis B-induced liver fibrosis: A proof-of-concept study. SLAS Technol. 2020, 25, 474-483. [CrossRef] [PubMed]

66. Wáng, Y.X.J. Living tissue intravoxel incoherent motion (IVIM) diffusion MR analysis without $\mathrm{b}=0$ image: An example for liver fibrosis evaluation. Quant. Imaging Med. Surg. 2019, 9, 127-133. [CrossRef] [PubMed]

67. Huang, H.; Zheng, C.J.; Wang, L.F.; Che-Nordin, N.; Wáng, Y.X.J. Age and gender dependence of liver diffusion parameters and the possibility that intravoxel incoherent motion modeling of the perfusion component is constrained by the diffusion component. NMR Biomed. 2020, e4449. [CrossRef]

68. Hayashi, T.; Miyati, T.; Takahashi, J.; Tsuji, Y.; Suzuki, H.; Tagaya, N.; Hiramoto, M.; Fukuzawa, K.; Tano, M.; Saitoh, S. Diffusion analysis with triexponential function in hepatic steatosis. Radiol. Phys. Technol. 2014, 7, 89-94. [CrossRef]

69. van Baalen, S.; Froeling, M.; Asselman, M.; Klazen, C.; Jeltes, C.; van Dijk, L.; Vroling, B.; Dik, P.; Ten Haken, B. Mono, bi- and tri-exponential diffusion MRI modelling for renal solid masses and comparison with histopathological findings. Cancer Imaging 2018, 18, 44. [CrossRef] [PubMed] 